\title{
Sequence characteristics and phylogenetic analysis of H9N2 subtype avian influenza $A$ viruses detected from poultry and the environment in China, 2018
}

\author{
Xiaoyi Gao ${ }^{1,2}$, Naidi Wang ${ }^{1}$, Yuhong Chen ${ }^{3}$, Xiaoxue Gu ${ }^{1}$, Yuanhui Huang ${ }^{4}$, Yang Liu ${ }^{1}$, Fei Jiang ${ }^{1}$, Jie Bai ${ }^{1}$, Lu Qi \\ , Shengpeng Xin ${ }^{1}$, Yuxiang Shi ${ }^{2}$, Chuanbin Wang ${ }^{\text {Corresp., } 1}$, Yuliang Liu ${ }^{\text {Corresp. } 1}$ \\ ${ }^{1}$ National Veterinary Diagnostic Center, China Animal Disease Control Center, Beijing, P.R.China \\ 2 College of Life Sciences and Food Engineering, Hebei University of Engineering, Handan, Hebei, P.R.China \\ ${ }^{3}$ College of Animal Science and Technology, GuangXi University, Nanning, Guangxi, P.R.China \\ 4 College of Animal Science and Technology, Guangxi University, Nanning, Guangxi, P.R.China \\ Corresponding Authors: Chuanbin Wang, Yuliang Liu \\ Email address: nvdcwang@sina.com, ylliu0905@163.com
}

H9N2 subtype avian influenza A virus (AIV) is a causative agent that poses serious threats to both the poultry industry and global public health. In this study, we performed active surveillance to identify H9N2 AIVs from poultry (chicken, duck, and goose) and the environment of different regions in China, and we phylogenetically characterized the sequences. AIV subtype-specific reverse transcription polymerase chain reaction (RT-PCR) showed that $5.43 \%$ (83/1529) samples were AIV positive, and $87.02 \%(67 / 77)$ of which were H9N2 AIVs. Phylogenetic analysis revealed that all H9N2 field viruses belonged to the Y280-like lineage, exhibiting $93.9-100 \%$ and $94.6-100 \%$ of homology in the hemagglutinin (HA) gene and $94.4-100 \%$ and $96.3-100 \%$ in the neuraminidase (NA) gene, at the nucleotide (nt) and amino acid (aa) levels, respectively. All field viruses shared relatively lower identities with vaccine strains, ranging from $89.4 \%$ to $97.7 \%$. The aa sequence at the cleavage site (aa 333-340) in HA of all the isolated H9N2 AIVs was PSRSSRG/L, which is a characteristic of low pathogenic avian influenza virus (LPAIV). Notably, all the H9N2 field viruses harbored eight glycosylation sites, whereas a glycosylation site 218 NRT was missing and a new site 313 NCS was inserted. All field viruses had NGLMR as their receptor binding sites (RBS) at aa position 224-229, showing high conservation with many recentlyisolated H9N2 strains. All H9N2 field isolates at position 226 had the aa Leucine (L), indicating their ability to bind to sialic acid (SA) $\alpha$, a 2-6 receptor of mammals that poses the potential risk of transmission to humans. Our results suggest that H9N2 AIVs circulating in poultry populations that have genetic variation and the potential of infecting mammalian species are of great significance when monitoring H9N2 AIVs in China. 
1 Sequence characteristics and phylogenetic analysis of H9N2 subtype avian influenza A

2 viruses detected from poultry and the environment in China, 2018

3

4 Xiaoyi Gao ${ }^{1,2}$, Naidi Wang ${ }^{*}$, Yuhong Chen ${ }^{1,3}$, Xiaoxue $\mathrm{Gu}^{1}$, Yuanhui Huang ${ }^{1,3}$, Yang Liu ${ }^{1}$, Fei

5 Jiang ${ }^{1}$, Jie Bai ${ }^{1}, \mathrm{Lu} \mathrm{Qi}^{1}$, Shengpeng Xin ${ }^{1}$, Yuxiang Shi ${ }^{2}$, Chuanbin Wang ${ }^{1 \dagger}$, Yuliang Liu ${ }^{1 \dagger}$

6

7 National Veterinary Diagnostic Center, China Animal Disease Control Center, Beijing, China

$8{ }^{2}$ College of Life Sciences and Food Engineering, Hebei University of Engineering, Handan,

9 Hebei, China

$10{ }^{3}$ College of Animal Science and Technology, Guangxi University, Nanning, Guangxi, China

12 Corresponding authors:

13 Chuanbin Wang, Ph.D., National Veterinary Diagnostic Center, China Animal Disease Control

14 Center, Biomedical Base, Daxing District, Beijing, China

15 E-mail: nvdcwang@sina.com

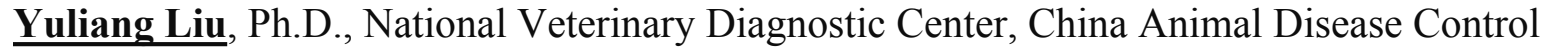

18 Center, Biomedical Base, Daxing District, Beijing, China

E-mail: ylliu0905@163.com

$21{ }^{*}$ Authors contributed equally to this work.

Running title: Phylogenetics of H9N2 AIVs in China 


\section{ABSTRACT}

H9N2 subtype avian influenza A virus (AIV) is a causative agent that poses serious threats to both the poultry industry and global public health. In this study, we performed active surveillance to identify H9N2 AIVs from poultry (chicken, duck, and goose) and the environment of different regions in China, and we phylogenetically characterized the sequences. AIV subtype-specific reverse transcription polymerase chain reaction (RT-PCR) showed that 5.43\% (83/1529) samples were AIV positive, and 87.02\% (67/77) of which were H9N2 AIVs. Phylogenetic analysis revealed that all H9N2 field viruses belonged to the Y280-like lineage, exhibiting $93.9-100 \%$ and $94.6-100 \%$ of homology in the hemagglutinin (HA) gene and 94.4$100 \%$ and $96.3-100 \%$ in the neuraminidase (NA) gene, at the nucleotide (nt) and amino acid (aa) levels, respectively. All field viruses shared relatively lower identities with vaccine strains, ranging from $89.4 \%$ to $97.7 \%$. The aa sequence at the cleavage site (aa 333-340) in HA of all the isolated H9N2 AIVs was PSRSSRG/L, which is a characteristic of low pathogenic avian influenza virus (LPAIV). Notably, all the H9N2 field viruses harbored eight glycosylation sites, whereas a glycosylation site 218 NRT was missing and a new site 313 NCS was inserted. All field viruses had NGLMR as their receptor binding sites (RBS) at aa position 224-229, showing high conservation with many recently-isolated H9N2 strains. All H9N2 field isolates at position 226 had the aa Leucine (L), indicating their ability to bind to sialic acid (SA) $\alpha$, a 2-6 receptor of mammals that poses the potential risk of transmission to humans. Our results suggest that H9N2 AIVs circulating in poultry populations that have genetic variation and the potential of infecting mammalian species are of great significance when monitoring H9N2 AIVs in China. 


\section{INTRODUCTION}

49

50

51

Avian influenza A virus (AIV), belonging to the family Orthomyxoviridae, carries a segmented, single-stranded, negative sense RNA genome with enveloped virions. The AIV genome contains eight segments with the ability to code various proteins: polymerase proteins (PB1, PB2, PA), nucleocapsid protein (NP), hemagglutinin (HA), neuraminidase (NA), matrix protein (M), and nonstructural protein (NS) (Jagger et al., 2012; Selman et al., 2012; Wise et al., 2012). Based on their virulence in chickens, AIVs can be categorized into low pathogenic avian influenza viruses (LPAIVs) and highly pathogenic influenza viruses (HPAIVs).

Chinese H9N2 LPAIV was first isolated from diseased chickens in Beijing in 1994 (Chen et al., 1997). Subsequently, H9N2 subtype AIV spread rapidly across China, posing a high risk to domestic poultry, special economic animals, and, occasionally, humans (Butt et al., 2005; Wang et al., 2018; Xu et al., 2007; Yi et al., 2012; Zhang et al., 2019). H9N2 subtype AIV can be transmitted and disseminated via the respiratory tract and contaminated wild bird feces, further complicating the control of this disease. In general, poultry infected with H9N2 virus only exhibit mild respiratory symptoms, but the wide spread of H9N2 subtype AIV could cause significant economic losses due to declined egg production, lower growth performance, increased risk of immunosuppression, and high mortality caused by coinfection with other respiratory pathogens (Liu et al., 2003). It has been documented that H9N2 AIV donates its inner genes to the lethal H5N1 influenza virus, as well as the H7N9 and H10N8 influenza virus, which 
67

could potentially lead to a human pandemic (Babakir-Mina et al., 2014; Chen et al., 2014; Cui et al., 2020; Guan et al., 1999, Pu et al., 2015).

Currently, vaccination is the most effective strategy for H9N2 AIV prevention and control implemented in China and many other countries around the world. However, genetic recombination and antigenic variation are the most crucial explanations for mismatch between vaccine strains and dominant circulating strains, which at least partly explains the reduced efficacy of commercial vaccines against H9N2 AIV. Because of this, it is essential to continuously monitor the genetic evolution of H9N2 viruses. Previous studies found that the H9N2 virus preferred to bind human-type sialic acid (SA) receptors, and that the number of humans infected with H9N2 AIV has increased in China in recent years (Li et al., 2017). The universal method classified H9N2 viruses into two major lineages, the North American lineage and the Eurasian lineage. The Eurasian lineage consists of four lineages: KR323-like (e.g., A/Chicken/Korea/38349-p96323/96), Y439-like (e.g., A/Duck/Hong Kong/Y439/1997), Y280like (e.g., A/Duck/Hongkong/Y439/97), and G1-like (e.g., A/Quail/Hong Kong/G1/97) (Guan et al., 1999). The Y280-like lineage was made up of five clades: A/chicken/Beijing/1/94-like (BJ/94-like), A/Chicken/Shandong/1998 (SD98-like), A/Chicken/HongKong/G9/1997 (G9-like), A/Chicken/Shanghai/F/1998 (SH98-like), and Y280-like. The BJ94-like lineage was substituted with the SH98-like lineage starting in 2004 (Zhang et al., 1997). The other method was established based on the evolutionary distance between the HA sequences of wild type isolates and classical strains. It was recently reported that the lineages h9.4.2.5 and h9.4.2.6 were dominant in China (Chen et al., 2013; Jiang et al., 2016; Shen et al., 2015). 
The AIV HA protein is a critical antigen associated with hemagglutinating activity and the adsorption and penetration of viral infections (Post et al., 2013; Xia et al., 2017). The NA protein mainly promotes the release of virus particles and prevents the aggregation of progeny virus particles by hydrolyzing sialic acid residues on the surface of viruses and cells. In this study, we conducted an active surveillance of AIV. Using RT-PCR, sequencing, virus isolation, and genetic analysis software, we analyzed the HA and NA of H9N2 subtype AIVs in different poultry species and environmental samples from different provinces in the eastern regions of China, aiming to explore their genetic relationship. We detected genetic variations in the H9N2 viruses, especially in the HA gene, from healthy poultry. Therefore, we suggest that the continuous surveillance of H9N2 AIVs in poultry farms be enhanced.

\section{MATERIALS AND METHODS}

\section{Samples and treatment}

Field sample collection was approved by the Chinese Animal Disease Control Center [CADC (surveillance) (2018) No. 53]. A total of 1,529 oropharyngeal and cloacal swab samples were collected from healthy chickens, ducks, geese, pigeons, and the environment from the live bird markets (LBM) in Shandong, Zhejiang, Hubei, and Jiangxi provinces, China, in 2018. Of the 1,529 samples, 20 were collected from the LBM environment. The swabs were placed into PBS containing $1 \%$ penicillin-streptomycin, stored in a cold environment with ice bags, transported to the laboratory within $24 \mathrm{~h}$, and immediately frozen at $-80^{\circ} \mathrm{C}$ before detection. The detailed information about the collected samples is shown in Table 1. All swabs were centrifuged at $3,000 \mathrm{rpm}$ for $10 \mathrm{~min}$ at $4^{\circ} \mathrm{C}$, and the supernatant of each sample was harvested and used for 
109

110

111

112

113

114

115

116

117

118

119

120

121

122

123

124

125

126

127

128

129

RNA extraction and subsequent RT-PCR. The AIV in the samples that were detected to be

positive for the H9N2 subtype by RT-PCR and sequencing were inoculated into 9-day-old specific-pathogen-free (SPF) embryonated chicken eggs (Beijing Merial Vital Laboratory Animal Technology Co., Ltd., Beijing, China) at a volume of $0.2 \mathrm{~mL} / \mathrm{egg}$. The inoculated chicken embryos were incubated at $37^{\circ} \mathrm{C}$ at a humidity of $50-60 \%$ and were monitored every day. The embryonated chicken eggs died between 24 and 144 hours post-inoculation (hpi), were timely collected, and were chilled for 24 hours. Subsequently, the allantoic fluid was harvested from the allantoic cavities of all embryonated eggs and purified by centrifugation at $4^{\circ} \mathrm{C}$ and $3,000 \times \mathrm{rpm}$ for $10 \mathrm{~min}$. The allantoic fluid was then used for hemagglutination and hemagglutination inhibition (HI) tests.

\section{RNA extraction, RT-PCR, and sequencing}

Viral RNA was extracted using the QIAamp Viral RNA Mini Kit (Qiagen, Hilden, Germany) according to the manufacturer's protocol. Primers were synthesized by Genewiz Co. Ltd., Suzhou, China. First, the partial NP gene fragment, with an expected size of $330 \mathrm{bp}$, was amplified according to the Agricultural Standard of China (standard ID: NY/T 772-2013). The

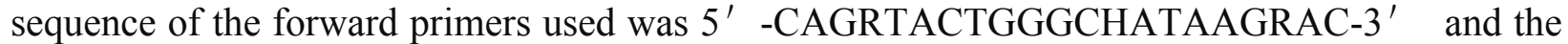
reverse primer sequence was $5^{\prime}$-GCATTGTCTCCGAAGAAATAAG-3' ${ }^{\prime}$. A reaction system with a volume of $20 \mu \mathrm{L}$ was prepared for one-step RT-PCR, consisting of $10 \mu \mathrm{L}$ of $2 \times$ buffer, $0.8 \mu \mathrm{L}$ of $\mathrm{Taq}^{\mathrm{TM}}$ polymerase, $0.8 \mu \mathrm{L}$ of forward and reverse primer mix $(10 \mathrm{pmol} / \mu \mathrm{L}$ each $), 0.2 \mu \mathrm{L}$ of AMV reverse transcriptase (TaKaRa, Japan), $0.2 \mu \mathrm{L}$ of RNasin ribonuclease inhibitor (Promega, Madison, USA), $2 \mu \mathrm{L}$ of RNA template, and $6 \mu \mathrm{L}$ of nuclease-free water (TaKaRa, 
130 Japan). All reagents were mixed gently and one step RT-PCR was conducted by incubating the

131 mixture at $42^{\circ} \mathrm{C}$ for $45 \mathrm{~min}$ for reverse-transcription (RT), followed by initial denaturation at

$13294^{\circ} \mathrm{C}$ for $3 \mathrm{~min}$, and 35 cycles of $94^{\circ} \mathrm{C}$ for $30 \mathrm{~s}, 52^{\circ} \mathrm{C}$ for $30 \mathrm{~s}$, and $72^{\circ} \mathrm{C}$ for $30 \mathrm{~s}$, and final extension

133 was $72^{\circ} \mathrm{C}$ for $8 \mathrm{~min}$. All AIV-positive samples were selected and further detected using one-step

134 RT-PCR and primers Bm-HA-F (5' -TATTCGTCTCAGGGAGCAAAGCAGGG-3' $)$ and

135 Bm-HA-R (5' -ATATCGTCTCGTATTAGTAGAAACAAGGGTGTTTT-3' $)$ to amplify the

136 open reading frame (ORF) of the AIV HA gene fragment with an expected size of approximately

$1371.7 \mathrm{~kb}$, as well as primers Ba-NA-1 (5' -TATTGGTCTCAGGGAGCAAAAGCAGGAGT-3' )

138 and Ba-NA-R (5' -ATATGGTCTCGTATTAGTAGAAACAAGGAGTTTTTT-3' ) to amplify

139 the ORF of the NA gene fragment with an expected size of approximately $1.4 \mathrm{~kb}$ (Hoffmann et al.,

140 2001). Briefly, a reaction system with a volume of $50 \mu \mathrm{L}$ was prepared for RT-PCR, consisting

141 of $25 \mu \mathrm{L}$ of Premix $\operatorname{Taq}^{\mathrm{TM}}$ (TaKaRa, Japan), $0.4 \mu \mathrm{L}$ of AMV reverse transcriptase (TaKaRa,

142 Japan), $0.6 \mu \mathrm{L}$ of RNasin ribonuclease inhibitor (Promega, Madison, USA), $0.1 \mu \mathrm{L}$ of reverse

143 primer, $0.1 \mu \mathrm{L}$ of forward primer, $18.2 \mu \mathrm{L}$ of nuclease-free water (TaKaRa, Japan), and $4 \mu \mathrm{L}$ of

144 RNA. All reagents were mixed gently and incubated at $42^{\circ} \mathrm{C}$ for $45 \mathrm{~min}$ for RT. The PCR

program was initial denaturation at $95^{\circ} \mathrm{C}$ for $3 \mathrm{~min}$, followed by 35 cycles of $94^{\circ} \mathrm{C}$ for $30 \mathrm{~s}, 56^{\circ} \mathrm{C}$

146 for $30 \mathrm{~s}$, and $68^{\circ} \mathrm{C}$ for $2 \mathrm{~min} 30 \mathrm{~s}$, and final extension was $72^{\circ} \mathrm{C}$ for $10 \mathrm{~min}$. Allantoic fluid

harvested from embryonated SPF chicken eggs (purchased from Charles River, Beijing, China)

and H9N2 subtype avian influenza virus strain A/Turkey/Wisconsin/1/1966 (purchased from

ATCC) were used as negative and positive controls for the aforementioned RT-PCR, 
151 Kit (TaKaRa, Japan). The purified RT-PCR products were quantified using a Nanodrop 2000

152 (Thermo Fisher) and sent to Genewiz Co. Ltd. (Suzhou, China) for sequencing.

153

154

155

156

157

158

159

160

161

162

163

164

165

166

167

168

169

170

171

\section{Phylogenetic analysis}

The nucleotide (nt) and amino acid (aa) homologies were assessed using the MegAlign Clustal W method in MegAlign. MEGA7.0 was used for phylogenetic tree construction using the neighbor-joining method with Kimura's two-parameter distance model and 1,000 bootstrap replicates (Xia et al., 2017). The trees included recently-isolated H9N2 AIV strains from China, major ancestral H9N2 AIV strains, and other reference H9N2 AIV strains. Reference sequences were obtained from the Global Initiative on Sharing All Influenza Data (GISAID) and GenBank. BioEdit program version 7.0 was used for genomic analysis.

\section{Antigenicity analysis}

The antigenicity of the selected field H9N2 isolates was detected using HA and HI tests.

\section{RESULTS}

\section{RT-PCR}

To conduct surveillance on H9N2 subtype AIVs, a total of 1,529 pharyngeal and cloacal swabs, as well as environmental LBM samples, were collected from Zhejiang, Hubei, Shandong, and Jiangxi provinces, China. RT-PCR detection of these samples determined that 83 isolates were positive for AIV, and 87.02\% (67/77) of AIV-positive isolates were H9N2 subtypes, while Sanger sequencing determined that $6.49 \%(5 / 77), 5.19 \%(4 / 77)$, and $1.30 \%(1 / 77)$ samples were H7N9, H3N6, and H4N6 subtypes, respectively. It should be noted that no HA and NA gene fragments could be amplified in six AIV-positive samples for unknown reasons. No H9N2 AIVs 
172 were detected in the 381 samples from Zhejiang province, and the majority of H9N2 AIV 173 positive samples $(56.82 \%(24 / 44))$ came from Hubei province. Our results showed that $25.00 \%$

174 175 and $18.18 \%$ of H9N2 AIV positive samples originated from Shandong and Jiangxi provinces, respectively. Notably, all H9N2 AIV-positive samples were isolated from chickens, except for two viruses found in ducks, one virus from a goose, and one from the environment.

\section{Phylogenetic analysis of HA}

We performed sequence alignment and analysis of HA and NA of all isolated H9N2 AIVs. As shown in Fig. 1, all H9N2 viruses belonged to the Y280-like lineage whose representative strain was A/Duck/HongKong/Y280/97. Overall, the HA homologies at the nt and aa levels were 93.6$100 \%$ and $93.8-100 \%$, respectively (Fig. S1A). Interestingly, all field H9N2 viruses shared relatively lower identities of 89.4-90.6\%, 91.4-92.2\%, 94.5-95.7\%, 94.6-95.4\%, 95.7-97.7\%, and 95.7-97.7\% for the vaccine strains A/Chicken/Guangdong/SS/94,
A/Chicken/Shandong/YB06/2006,
A/Chicken/
Guangdong/Y4/2009,

A/Chicken/Shandong/HL/2010,

A/Chicken/Jiangsu/WJ57/2012,

and A/Chicken/Jiangsu/SZ0207/2013, respectively (Fig. S1B). A phylogenetic tree was constructed based on the HA sequences, utilizing a top 30\% cutoff. The results indicated that all isolated H9N2 viruses were divided into three distinct clusters (Fig. 1A). A total of 17 H9N2 viruses, ten of which originated from Shandong and seven from Hubei, were clustered into a separate branch with a lower homology rate compared to others. Interestingly, our results demonstrated further genetic distance between the isolated strains and the representative Y280 strain or the vaccine strains (Fig. 1). H9N2 viruses isolated from Hubei and Jiangxi were divided into two clusters and, compared to the isolated strains from recent years, a further genetic relationship was indicated between the field strains. 
195

196

197

198

199

200

201

202

203

204

205

206

207

208

209

210

211

212

213

214

215

216

217

The cleavage site (aa 333-340) in the HA of all the H9N2 isolates was PSRSSR/GL, a typical characteristic of LPAIV (data not shown). A total of eight potential glycosylation sites were identified in the HA of all isolates. Interestingly, a 218NRT site was missing and a 313NCS and a 551GSC sites were inserted when compared to a classical Y280 strain, such as A/Duck/HongKong/Y280/97 (Table 2). At the potential glycosylation site 141, there were 29 isolates sharing the same aa sequence VSY with Y280, whereas the aa sequence VTY was present in the rest of the strains (Table 2). The HA genes of the H9 subtype AIVs at positions 109, 161, 163, 191, 198, 202, 203, 146-150, and 232-237 formed an RBS pouch structure (Matrosovich et al., 2007). The RBS (aa 232-237) in the HA of the field isolates was NGLMGR, which was highly conservative (Table 2 ). We observed four mutation types (T/S/L/A) at aa site 198 after aligned with the HA sequence of the recently isolated viruses (Table 2). Notably, mutations were found in four sites that were related to the specific SA of the HA binding, namely $\mathrm{S} / \mathrm{T}$ at position $143, \mathrm{D} / \mathrm{S}$ at $145, \mathrm{~T} / \mathrm{K}$ at 149 , and $\mathrm{N} / \mathrm{G}$ at 201 (Table 2). These various mutations suggest that the virus has adapted to the host or escaped during vaccination. Leucine (L) was the aa at position 234 (e.g., 226, H3 numbering) in the HA gene sequence of all field strains, indicating its ability to preferentially bind to $\alpha-2,6$ linked SA, a mammalian species receptor

(Couceiro et al., 1993; Matrosovich et al., 1997; Stevens et al., 2006; Teng et al., 2016). Additionally, all isolates carried 225 Glycine (G) in the HA segment (data not shown), which exhibited a human-type receptor-binding property.

\section{Phylogenetic analysis of NA}

The result of the phylogenetic analysis of NA is shown in Fig. 1B. The isolate A/Chicken/Shandong/C82/2017 exhibited high homology with A/Duck/Hong Kong/Y439/1997. Overall, the NA sequence of field isolates somewhat exhibited a genetic distance with that of 
218 vaccine strains (Fig. 1B). The H9N2 field virus identities at the nt and deduced aa sequence of

219 NA ranged from 94.4-100\% and 94.6-100\%, respectively (Fig. S1C). The NA sequence

220 homologies between the isolates and commercial vaccine strain A/Chicken/Guangdong/SS/94,

221 A/Chicken/Shandong/HL/2010, A/Chicken/Jiangsu/WJ57/2012, and

222 A/Chicken/Jiangsu/SZ0207/2013 were 90.7-91.5\%, 92.6-93.4\%, 92.0-92.7\%, and 95.9-97.1\%,

223 respectively (Fig. S1D). This result indicated that there was genetic variation between the NA

224 gene of field isolates and the vaccine strains.

225 The majority of isolates contained seven potential glycosylation sites, which was

226 comparable to that of the Y280-like isolates. The aa sequence of $365 \mathrm{GSR} / \mathrm{DSR}$ at the potential

227 glycosylation sites was substituted by 399WSG, while an isolate named

228 A/Chicken/Shandong/C54/2017 possessed 10 potential glycosylation sites (plus 2PIQ, 261ISP,

229 and 44PSN) when compared to the classical Y280-like isolates. It was shown that strains

230 A/Chicken/Jiangxi/C19/2017, A/Chicken/Hubei/65/2017, and A/Chicken/Jiangxi /C42/2017

231 lacked 44PSN aa.

\section{Antigenicity analysis}

233 To understand the antigenicity of the H9N2 viruses, the supernatant from 45 H9N2-positive

234 samples were selected and inoculated into 9-day-old SPF chicken eggs, and the HA/HI test was

235 performed. The results of the HI test are shown in Fig. 2. The 45 isolates exhibited a positive

236 reaction with the standard serum antibody of H9 AIV, developed by Harbin Veterinary Research

237 Institute (HVRI), Chinese Academy of Agricultural Sciences (CAAS), China. The HI titer

238 ranged from $7 \log 2$ to $10 \log 2$, and the averaged titer was $8.2 \log 2$. Notably, four viruses reacted 
239

240

241

242

244

245

246

247

248

249

250

251

252

253

254

255

256

257

258

259

260

with the positive serum of the H5 subtype AIV, as demonstrated by an averaged HI titer of 6Log2. We found that nine field viruses reacted with the H7 AIV positive serum, with a titer range of $4 \log 2$ to $5 \log 2$. Interestingly, all viruses with the ability to react with the $\mathrm{H} 5$ positive serum could also react with the $\mathrm{H} 7$ positive serum. Four viruses reacted well with the H5, H7, and $\mathrm{H} 9$ antibodies, and five virus strains could only react with the $\mathrm{H} 7$ and $\mathrm{H} 9$ antibodies.

\section{DISCUSSION}

H9N2 viruses in the Y280 lineage have been spreading across China in recent years (Xue et al., 2014; Cong et al., 2017; Wang et al., 2011). Previous reports indicated that the major genotypes of H9N2 AIVs in China could be divided into five series: BJ/94-, G1-, BG-, F/98-, and Aq-series (Sun et al., 2010). In this study, a total of 67 out of 77 AIVs were detected to be H9N2 subtypes. A Y280 strain was selected as the reference strain to analyze the evolution of the HA and NA segments of H9N2 field isolates. Using the HA nucleotide sequence, a biological phylogenetic tree was constructed, and the phylogenetic analysis showed that the H9N2 isolates shared a relatively closer genetic relationship with the Y280 strain, and H9N2 isolates and the strain SH98 in the NA fragment showed the closest relatedness. All H9N2-positive samples were collected from Hubei, Jiangxi, and Shandong, but no AIV was detected in samples from Zhejiang. We hypothesized that the better biosafety management of farms and more effective animal disease control measures implemented in Zhejiang may partially explain the absence of AIV in the samples we detected. As shown in the phylogenetic tree in Fig. 1, the HA nucleotide sequence of H9N2 viruses from Shandong province differed significantly from the prevalent reference strains. The geographic location of Shandong province may explain this difference, since Shandong is located in an area along the coastline of the Bohai Sea where bird migration is 
261 more frequent. This likely increases the chance of reassessment of domestic H9N2 viruses with 262 other subtype AIVs, leading to the genetic variation of the H9N2 viruses. Poyang Lake is located 263 in Jiangxi province, meaning that a large number of waterfowls, e.g., ducks and geese, breed in 264 this area (Li et al., 2017). It has been well-documented that H9N2 AIV provides internal genes to 265 other subtype AIVs such as H7N9 virus, resulting in a new generation of reassortant viruses that 266 pose an increased threat to public health (Pu et al., 2015; Su et al., 2015).

267 Inactivated vaccines against H9N2 avian influenza have been used in China for decades. However, active surveillance has shown that the H9N2 virus was frequently detected in samples collected from poultry farms, LBMs, and the environment, indicating that the currently-used vaccines for H9N2 avian influenza are not as effective as needed, and therefore need to be updated. The findings of this study supported this observation. These results suggest that new candidate vaccines that correspond better with dominantly circulating H9N2 AIVs need to be developed (Liu et al., 2002).

In our survey, all H9N2 isolates had cleavage sites of PSRSSRG/L, which was a characteristic of LPAIV. Potential glycosylation sites at the HA of H9N2 AIV were at aa positions $8,29,82,141,218$, and 298 (H9 numbering). Our result showed that, compared to the Y280 strain, the aa at the glycosylation site of 313 CSK and 551 GSC was inserted, while the aa of 218 RTF was deleted. The glycosylation site at 402 , which was reportedly related to the characteristics of H9N2 viruses (Kandeil et al., 2017), was not found in any virus analyzed in this study. N-linked glycosylation sites were confirmed to play critical roles in viral infectivity and host cell immune response. Particularly, the glycosylation site in the HA cleavage site affected the cleavage capability of HA by protease, leading to a change in virulence (Owen et al., 
2007). The RBS is of great significance for host cellular receptor specificity and plays an important role in the generation of reassortant influenza viruses (Wang et al., 2016). The HA

RBS bears a certain degree of variation, mainly in $198 \mathrm{~V} / \mathrm{T} / \mathrm{S} / \mathrm{L} / \mathrm{A}$ and $168 \mathrm{~A} / \mathrm{S} / \mathrm{N} / \mathrm{E} / \mathrm{D} / \mathrm{F}$. RBS is

closely related to the host cell and virulence, and we speculate that it may have an intimate relationship with the escape immune defense mechanism that AIV induces in hosts after vaccination (Liu et al., 2002). HA is the most abundant protein on the surface of the virion, and exhibits specific binding affinities for the different SA-linked glycoproteins that are expressed on the cell-surface receptors. AIVs preferentially bind to SA linked to the terminal oligosaccharide by an $\alpha-2,3-$ linked bond (generally referred to as the avian receptor), while human influenza virus strains favor the $\alpha-2,6$-linked SA receptor (generally referred to as the human receptor) (Matrosovich et al., 1997; Stevens et al., 2006). It was previously found that the intestinal epithelial cells of poultry were mainly distributed with $\alpha-2,3$ receptors (Ito et al., 2000), while the epithelial cells of human upper respiratory tracts mainly had $\alpha-2,6$ receptors (Couceiro et al., 1993). Therefore, the prerequisite for AIV infection in humans is a mutated receptor binding site of the HA protein, with the ability to bind to the $\alpha$-2,6-linked SA receptor, either naturally or artificially. A switch from a-2,3 to a-2,6 binding specificity requires several HA mutations, and the mechanism of this situation is complex (Shi et al., 2014). There are $\alpha-2,3$ receptors on the human epithelial cells of the lower respiratory tract, alveoli, and lung macrophages (Shinya et al., 2006; Van et al., 2006). Notably, the leucine (Leu) residue at position 226 of the HA protein creates a more hydrophobic environment than that of the HA of AIV, which likely accounts for the absence of water molecules in this region. Furthermore, the shortest distance between the 
304 side-chains of Leu-226 and C6 of the ligand are too long to generate a significant hydrophobic

305

306

307

308

309

310

311

312

313

314

315

316

317

318

319

320

321

322

323

324

325

interaction to facilitate the binding of the $\alpha-2,6$-linked ligand. In contrast, in unliganded avian

HA, Gln-226 coordinates a water molecule that is very close to the position occupied by Gal-2 in

the human HA-human receptor complex. This suggests that human HAs benefit from acquiring

Leu at position 226 because human receptors can bind without the need to displace water. The

most obvious explanation for the weaker binding of avian receptors, also observed in binding

assays (Matrosovich et al., 2006), lies in the positioning of the hydrophobic Leu-226 underneath

where glycosidic oxygen would normally occupy the $\alpha-2,3$-linked avian receptor. Avian $\alpha-2,3-$

linked receptors tend to bind in a trans conformation at the Sia-1-Gal-2 glycosidic bond, while

human $\alpha$-2,6-linked receptors adopt a cis conformation, meaning that one of the loan pairs of

electrons of the glycosidic oxygen in the avian receptor is oriented toward Gln-226, rather than

away from the protein that is toward the solvent, as in the case of the human receptor (Eisen et

al., 1997; Liu et al., 2009). Additionally, because HA Q234L (H9 numbering) holds a high

affinity with $\alpha-2,6 \mathrm{SA}$ of human mucous cells, they have the ability to infect humans.

8 The location and number of HA glycosylation sites and the RBS on influenza viruses were determined via virus genomic sequence. The replication of the virus was initiated and promoted by RNA-dependent RNA polymerase. The lack of self-correction of polymerase resulted in an increased rate of genetic mutations in AIV when compared to other viruses (Guan et al., 1999; Liu et al., 2003; Zhang et al., 2016). If mutations occurred on HA glycosylation sites and/or RBS, new amino acids were often introduced or deleted. If the newly-occurring oligosaccharide chain was near the glycosylation site due to gene mutations, the original structure of the antigenic determinant was destroyed by the appearance of the oligosaccharide chain, and the antibody 
326 produced by the original vaccine was not neutralized, triggering new epidemics (Zhang et al., 327 2018).

328 The results in this study showed that the NA gene sequence of H9N2 field isolates had the 329 highest homology with the classical strain SH98, while the HA gene had the highest homology 330 with the Y280 strain. This result indicated that the field isolates were reassortant viruses. The 331 NA gene of the field isolates exhibited more significant genetic variations than the prevalent and 332 vaccine strains used in recent years, and formed a distinct evolutionary branch. The circulating isolates examined in our survey were compared to the classical strains in the aa 63-65 in the stem of NA, and showed different potential glycosylation sites of the field isolates. Most field isolates had seven potential glycosylation sites, but the classical strain had lost $61 \mathrm{NTE}$ and had a new 365GSR site introduced. Additionally, our data showed three strains that lacked 44PSN, and one isolate, A/Chicken/Shandong/C54/2017, that had nine glycosylation sites and a new glycosylation site 2PIQ, when compared to the classical H9N2 AIV isolates. The function of NA was tantamount when cutting off the connection between HA and host cells and when facilitating the release of progeny virus. The loss of the NA stem led to altered viral virulence and enhanced infectivity to host cells (Qi et al., 2006). Our findings underscored the necessity to continuously update H9N2 AIV vaccines with the NA from prevalent strains.

343 The results of the HI assay depicted in this study suggested that the HA and NA of H9N2 field 344 isolates were constantly evolving and reassorting. Our HI test results suggest the possibility of 345 reassortment between the $\mathrm{H} 9$ and $\mathrm{H} 5 \mathrm{HA}$ gene fragments. The H7 subtype AIV could not be 346 ruled out, which may have caused the cross immune response detected in this study. Given that 
347 the H9N2 virus could provide internal genes for $\mathrm{H} 7$ and/or H5 subtype HPAIVs, resulting in a

348 reassortant virus that may have the ability to infect humans, the mutation of the H9N2 virus

349 should not be ignored. In addition, nationwide compulsory vaccination programs that use

350 trivalent vaccines, namely (H5) Re-11/Re-12 + (H7) Re-3 inactivated vaccines, are currently

351 implemented in China for the prevention and control of H5 and H7 subtype HPAIV. The

352 compulsory vaccination campaign played an important role in HPAIV prevention and control in

353 China. Nevertheless, the H5 and H7 subtype HPAIVs are continuously evolving under the

354 pressure of immunization. Therefore, continuous monitoring of H9N2 AIVs and the timely updating of vaccines are of great importance for H9N2 subtype influenza prevention and control.

Our findings confirmed that LBMs are an ideal place for H9N2 and other subtype AIV reassortment, and LBM management should also be improved.

\section{ACKNOWLEDGEMENTS}

We are grateful to the anonymous reviewers for providing insightful comments on this paper.

REFERENCES

Babakir-Mina M, Monte SD, Presti AL, Cella E, Ciccozzi M. 2014. Phylogenetic and evolutionary analysis of influenza a H7N9 virus. New Microbiologica 37, 369

Butt KM, Smith GJ, Chen H, Zhang LJ, Leung YH, Xu KM, Lim W, Webster RG, Yuen

KY, Peiris JS, Guan Y. 2005. Human infection with an avian H9N2 influenza A virus in Hong 
369

370

371

372

373

374

375

376

377

378

379

380

381

382

383

384

385

386

387

388

389

390

391

392

393

394

395

396

397

Chen PL, Zhang ZJ. 1997. Isolation and serological identification of avian influenza A virus from chickens. Chinese Poultry 11:4-6

Cong YL, Zhong Y, Sun YY, Ding Z. 2017. Epidemiology of H9N2 subtype avian influenza virus and its vaccine. Chinese Journal of Veterinary Medicine 37: 386-392

Couceiro JN, Paulson JC, Baum LG. 1993. Influenza virus strains selectively recognize sialyloligosaccharides on human respiratory epithelium; the role of the host cell in selection of hemagglutinin receptor specificity. Virus Research 29(2): 155-65

Cui YF, Li YL, Li MH, Zhao L, Wang DL, Tian JM, XBai XL, Ci YP, Wu SS, Wang F, Chen XM, Ma SJ, Qu ZY, Yang C, Liu LL, Shi JZ, Guan YT, Zeng XY, Tian GB, Cui PF, Deng GH, Jiang YP, Chen PC, Liu JX, Wang XR, Bao HM, Jiang L, Suzuki Y, Li CJ, Li YB, Chen HL. 2020. Evolution and extensive reassortment of H5 influenza viruses isolated from wild birds in China over the past decade. Emerging Microbes \& Infections, 9: 1793-1803

Chen R, Han Z, Li L, Liu Y, Pan W, Zhang W, Xu J, He D, Tang Z. 2013. Genetic variation and phylogenetic analysis of hemagglutinin genes of $\mathrm{H} 9$ avian influenza viruses isolated in China during 2010-2012. Veterinary Microbiology, 165 (3-4): 312-318

Eisen MB, Sabesan S, Skehel JJ, Wiley DC. 1997. Binding of the influenza A virus to cellsurface receptors: structures of five hemagglutinin-sialyloligosaccharide complexes determined by X-ray crystallography. Virology 232(1): 19-31

Gong T, Shi Y, Ni X, Li J, Zhou J, Fan J, Wu J, Zhou X, Hu M, Wan J, Yang W, Li D, Wu G, Feng Z, Gao GF, Wang Y, Jin Q, Liu M, Shu Y. 2014. Clinical and epidemiological characteristics of a fatal case of avian influenza A H10N8 virus infection: a descriptive study. The Lancet 383: 22-28 DOI org/10.1016/S0140-6736(14)60111-2.

Guan Y, Shortridge KF, Krauss S, Webster RG. 1999. Molecular characterization of H9N2 influenza viruses: were they the donors of the "internal" genes of H5N1 viruses in Hong Kong?. Proceedings of the National Academy of Sciences of the United States of America 96:9363-9367

Hoffmann E, Stech J, Guan Y, Webster RG, Perez DR. 2001. Universal primer set for the full-length amplification of all influenza A viruses. Archives of Virology 146:2275-2289 
405

406

407

408

409

410

411

412

413

414

415

416

417

418

419

420

421

422

423

424

425

426

427

428

429

430

431

432

433

434

435

436

437

438

439

440

Ito T, Suzuki Y, Suzuki T, Takada A, Horimoto T, Wells K, Kida H, Otsuki K, Kiso M, Ishida H, Kawaoka Y. 2000. Recognition of N-glycolylneuraminic acid linked to galactose by the $\alpha 2,3$-linkage is associated with intestinal replication of influenza A virus in ducks. J Virology 74(19): 9300-5

Jagger BW, Wise HM, Kash JC, Walters KA, Wills NM, Xiao YL, Dunfee RL, Schwartzman L M, Ozinsky A, Bell GL, Dalton RM, Lo A, Efstathiou S, Atkins JF, Firth AE, Taubenberger JK, Digard P. 2012. An overlapping protein-coding region in influenza A virus segment 3 modulates the host response. Science 337:199-204

Jiang WM, Wang Y, Li JP, Hou GY, Peng C, Liu S, Wang SC, Huang BX, Chen JM. 2017. Epidemiological investigation and analysis of avian influenza in a live poultry market in East China from 2014 to 2016. Chinese Animal Quarantine 34: 14-18.

Kandeil A, El-Shesheny R, Maatouq A, Moatasim Y, Cai Z, McKenzie P, Webby R, Kayali G, Ali MA. 2017. Novel reassortant H9N2 viruses in pigeons and evidence for antigenic diversity of H9N2 viruses isolated from quails in Egypt. Journal of General Virology 98:548-562

Li C, Wang S, Bing G, Carter RA, Wang Z, Wang J, Wang C, Wang L, Wu G, Webster RG, Wang Y, Sun H, Sun Y, Liu J, Pu J. 2017. Genetic evolution of influenza H9N2 viruses isolated from various hosts in China from 1994 to 2013. Emerging Microbes \& Infections 6:e106

Liu HQ, Huang Y, Cheng J, Peng DX, Jia LJ, Zhang RK, LIU XF. 2002. Genetic variation of HA gene of H9N2 subtype avian influenza virus under vaccine selection pressure. Chinese Journal of Virology 18: 149-154

Liu J, Stevens DJ, Haire LF, Walker PA, Coombs PJ, Russell RJ, Gamblin SJ, Skehel JJ. 2009. Structures of receptor complexes formed by hemagglutinins from the Asian influenza pandemic of 1957. Proc Natl Acad Sci USA 106(40): 17175-80

Matrosovich M, Matrosovich T, Uhlendorff J, Garten W, Klenk HD. 2007. Avian-virus-like receptor specificity of the hemagglutinin impedes influenza virus replication in cultures of human airway epithelium. Virology 361(2):384-390

Matrosovich M, Tuzikov A, Bovin N, Gambaryan A, Klimov A, Castrucci MR, Donatelli I, Kawaoka Y. 2000. Early alterations of the receptor-binding properties of H1, H2, and H3 avian 
441 influenza virus hemagglutinins after their introduction into mammals. Journal of Virology 74(18):

Matrosovich MN, Gambaryan AS, Teneberg S, Piskarev VE, Yamnikova SS, Lvov DK,

Robertson JS, Karlsson KA. 1997. Avian influenza A viruses differ from human viruses by recognition of sialyloligosaccharides and gangliosides and by a higher conservation of the HA receptor-binding site. Virology 233(1): 224-34

Owen RE, Yamada E, Thompson CI, Phillipson LJ, Thompson C, Taylor E, Zambon M, Osborn HM, Barclay WS, Borrow P. 2007. Alterations in receptor binding properties of recent human influenza H3N2 viruses are associated with reduced natural killer cell lysis of infected

Post J, de Geus ED, Vervelde L, Cornelissen JB, Rebel JM. 2013. Systemic distribution of different low pathogenic avian influenza (LPAI) viruses in chicken. Virology Journal 10:23

Pu J, Sun H, Qu Y, Wang C, Gao W, Zhu J, Sun Y, Bi Y, Huang Y, Chang KC, Cui J, Liu J. 2017. M gene reassortment in $\mathrm{H} 9 \mathrm{~N} 2$ influenza virus promotes early infection and replication: contribution to rising virus prevalence in chickens in China. Journal of Virology 91:e02055-16

Pu J, Wang S, Yin Y, Carter RA, Wang J, Xu G, Sun H, Wang M, Wen C, Wei Y, Wang D, Zhu B, Lemmon G, Jiao Y, Duan S, Wang Q, Du Q, Sun M, Bao J, Sun Y, Zhao J, Zhang H, Wu G, Liu J, Webster RG. 2015. Evolution of the H9N2 influenza genotype that facilitated the genesis of the novel H7N9 virus. Proceedings of the National Academy of Sciences of the United States of America 112:548-553

Qi X, Lu CP. 2006. Genetic characterization of novel reassortant H1N2 influenza A viruses isolated from pigs in southeastern China. Archives of Virology 151:2289-2299

Selman M, Dankar SK, Forbes NE, Jia JJ, Brown EG. 2012. Adaptive mutation in influenza A virus non-structural gene is linked to host switching and induces a novel protein by alternative splicing. Emerging Microbes \& Infections 1:e42

Shen H, Yan Z, Zeng F,Liao C,Zhou Q,Qin J,Xie Q,Bi Y,Chen F. 2015. Isolation and phylogenetic analysis of hemagglutinin gene of H9N2 influenza viruses from chickens in South China from 2012 to 2013. Journal of Veterinary Science, 2015, 16(3):317-324

Peer) reviewing PDF | (2020:07:50819:2:0:NEW 2 Sep 2021) 
Shi, Y, Wu Y, Zhang W, Qi J, Gao GF. Enabling the 'host jump': structural determinants of receptor-binding specificity in influenza A viruses. Nature Review Microbiology 12: 822-831

Shinya K, Ebina M, Yamada S, Ono M, Kasai N, Kawaoka Y. 2006. Avian flu: influenza virus receptors in the human airway. Nature 440 (7083): 435-6

Stevens J, Blixt O, Glaser L, Taubenberger JK, Palese P, Paulson JC, Wilson IA. 2006. Glycan microarray analysis of the hemagglutinins from modern and pandemic influenza viruses reveals different receptor specificities. Journal of Molecular Biology 355(5): 1143-55

Van Riel D, Munster VJ, de Wit E, Rimmelzwaan GF, Fouchier RAM, Osterhaus ADME,

Wang M. 2016. Receptor binding properties of H10 and H9 influenza virus. China Agricultural 511

Sun Y, Pu J, Jiang Z, Guan T, Xia Y, Xu Q, Liu L, Ma B, Tian F, Brown EG, Liu J. 2010. Genotypic evolution and antigenic drift of H9N2 influenza viruses in China from 1994 to 2008. Veterinary Microbiology 146(3-4):215-225

Su W., Wang C., Luo J., Zhao Y., Wu Y., Chen L., Zhao N., Li M., Xing C., Liu H., Zhang H., Chang Y. F., Li T., Ding H., Wan X., He H. 2015. Testing the effect of internal genes derived from a wild-bird-origin H9N2 influenza A virus on the pathogenicity of an A/H7N9 virus. Cell Rep 12(11):1831-1841

Teng Q, X.D., Shen W, Liu Q, Rong G, Li X, Yan L, Yang J, Chen H, Yu H, Ma W, Li Z. 2016. A single mutation at position 190 in hemagglutinin enhances binding affinity for human type sialic acid receptor and replication of H9N2 avian influenza virus in mice. Journal of Virology 90: 9806-9825

Kuiken T. 2006. H5N1 virus attachment to lower respiratory tract. Science 312(5772): 399

Wang D, Wang J, Bi Y, Fan D, Liu H, Luo N, Yang Z, Wang S, Chen W, Wang J, Xu S, Chen J, Zhang Y, Yin Y. 2018. Characterization of avian influenza H9N2 viruses isolated from ostriches (Struthio camelus). Scientific Reports 8: 2273

University. $\mathrm{Ph} . \mathrm{D}$. thesis. 
512 Wang YS, Li JL, Liang W, You YJ, Yang BS, Wu S, Zou LH, Liu H. 2011. Analysis of HA

513

514

515

516

517

518

519

520

521

522

523

524

525

526

527

528

529

530

531

532

533

534

535

536

537

538

539

540

541

542

543

544

545 gene variation of 13 strains of H9N2 subtype avian influenza virus. Chinese Journal of Poultry 33: $9-12$

Wise HM, Hutchinson EC, Jagger BW, Stuart AD, Kang ZH, Robb N, Schwartzman LM, Kash J C, Fodor E, Firth AE, Gog JR, Taubenberger JK, Digard P. 2012. Identification of a novel splice variant form of the influenza A virus M2 ion channel with an antigenically distinct ectodomain. PLoS Pathogens 8:e1002998

Xia J, Cui JQ, He X, Liu YY, Yao KC, Cao SJ, Han XF, Huang Y. 2017. Genetic and antigenic evolution of H9N2 subtype avian influenza virus in domestic chickens in southwestern China, 2013-2016. PLoS ONE 12:e0171564

Xu KM, Smith GJD, Bahl J, Duan L, Tai H, Vijaykrishna D, Wang J, Zhang JX, Li KS, Fan XH, Webster RG, Chen H, Peiris JSM, Guan Y. 2007. The genesis and evolution of H9N2 influenza viruses in poultry from southern China, 2000 to 2005. Journal of Virology 81: 10389-10401

Xue Y, Wang JL, Yan ZQ, Li GW, Chen SY, Zhang XB, Qin JP, Li HY, Chang S, Chen F, Bee YZ, Xie QM. 2014. Sequence and phylogenetic analysis of surface protein genes of emerging H9N2 influenza viruses isolated from poultry in two geographical regions of China. Virus Genes 48:479-485

Zhang J, Wu H, Zhang Y, Cao M, Brisse M, Zhu W, Li R, Liu M, Cai M, Chen J, Chen J. 2019. Molecular evolutionary and antigenic characteristics of newly isolated H9N2 avian influenza viruses in Guangdong province, China. Archives of Virology 164:607-612

Zhang J, Chen LG, Zhang Y, Sun QJ, Li RY, Bai MY, Lin WC, Xie QM. 2016. Study on the prevalence of H9N2 subtype Avian Influenza virus in different regions of China from 1997 to 2015. Chinese Poultry 38: 20-27

Zhang S, Chen QJ, Bi YH, Liu WJ, Sheng W, Zhang T, Li J. 2018. Genetic evolution of HA and NA genes of H9N2 subtype influenza virus in parts of Hunan in 2015. Chinese Journal of Biotechnology 34: 537-547 
547 Table 1. Geographic distribution and source species of H9N2 avian influenza viruses.

\begin{tabular}{|c|c|c|}
\hline No. & Name of virus isolate & Species \\
\hline 1 & A/Chicken/Hubei/76/2018 & Chicken \\
\hline 2 & A/Chicken/Hubei/81/2018 & Chicken \\
\hline 3 & A/Chicken/Hubei/61/2018 & Chicken \\
\hline 4 & A/Chicken/Hubei/127/2018 & Chicken \\
\hline 5 & A/Chicken/Shandong/C84/2018 & Chicken \\
\hline 6 & A/Duck/Jiangxi/D10/2018 & Duck \\
\hline 7 & A/Chicken/Shandong/C131/2018 & Chicken \\
\hline 8 & A/Chicken/Hubei/226/2018 & Chicken \\
\hline 9 & A/Chicken/Hubei/142/2018 & Chicken \\
\hline 10 & A/Chicken/Hubei/126/2018 & Chicken \\
\hline 11 & A/Chicken/Hubei/147/2018 & Chicken \\
\hline 12 & A/Chicken/Hubei/149/2018 & Chicken \\
\hline 13 & A/Chicken/Hubei/251/2018 & Chicken \\
\hline 14 & A/Chicken/Shandong/C54/2018 & Chicken \\
\hline 15 & A/Chicken/Hubei/95/2018 & Chicken \\
\hline 16 & A/Chicken/Hubei/261/2018 & Chicken \\
\hline 17 & A/Chicken/Hubei/80/2018 & Chicken \\
\hline 18 & A/Chicken/Hubei/160/2018 & Chicken \\
\hline 19 & A/Chicken/Shandong/C107/2018 & Chicken \\
\hline 20 & A/Chicken/Shandong/C169/2018 & Chicken \\
\hline 21 & A/Chicken/Jiangxi/C15/2018 & Chicken \\
\hline 22 & A/Chicken/Shandong/C79/2018 & Chicken \\
\hline 23 & A/Environment/Jiangxi/E15/2018 & Environment \\
\hline 24 & A/Chicken/Jiangxi/C19/2018 & Chicken \\
\hline 25 & A/Chicken/Shandong/C80/2018 & Chicken \\
\hline 26 & A/Chicken/Jiangxi/C16/2018 & Chicken \\
\hline 27 & A/Chicken/Hubei/146/2018 & Chicken \\
\hline 28 & A/Chicken/Hubei/78/2018 & Chicken \\
\hline 29 & A/Chicken/Jiangxi/C11/2018 & Chicken \\
\hline
\end{tabular}




\begin{tabular}{lll}
30 & A/Chicken/Hubei/131/2018 & Chicken \\
31 & A/Chicken/Hubei/92/2018 & Chicken \\
32 & A/Chicken/Jiangxi/C14/2018 & Chicken \\
33 & A/Chicken/Hubei/63/2018 & Chicken \\
34 & A/Chicken/Shandong/C126/2018 & Chicken \\
35 & A/Chicken/Hubei/65/2018 & Chicken \\
36 & A/Chicken/Hubei/107/2018 & Chicken \\
37 & A/Duck/Jiangxi/D1/2018 & Duck \\
38 & A/Chicken/Hubei/90/2018 & Chicken \\
39 & A/Chicken/Hubei/169/2018 & Chicken \\
40 & A/Chicken/Hubei/77/2018 & Chicken \\
41 & A/Chicken/Jiangxi/C42/2018 & Chicken \\
42 & A/Goose/Jiangxi/G1/2018 & Goose \\
43 & A/Chicken/Hubei/152/2018 & Chicken \\
44 & A/Chicken/Hubei/262/2018 & Chicken \\
45 & A/Chicken/Shandong/C82/2018 & Chicken \\
46 & A/Chicken/Hubei/251/2018 & Chicken \\
47 & A/Duck/Jiangxi/D13/2018 & Duck \\
48 & A/Chicken/Shandong/C131/2018 & Chicken \\
49 & A/Chicken/Hubei/85/2018 & Chicken \\
\hline
\end{tabular}




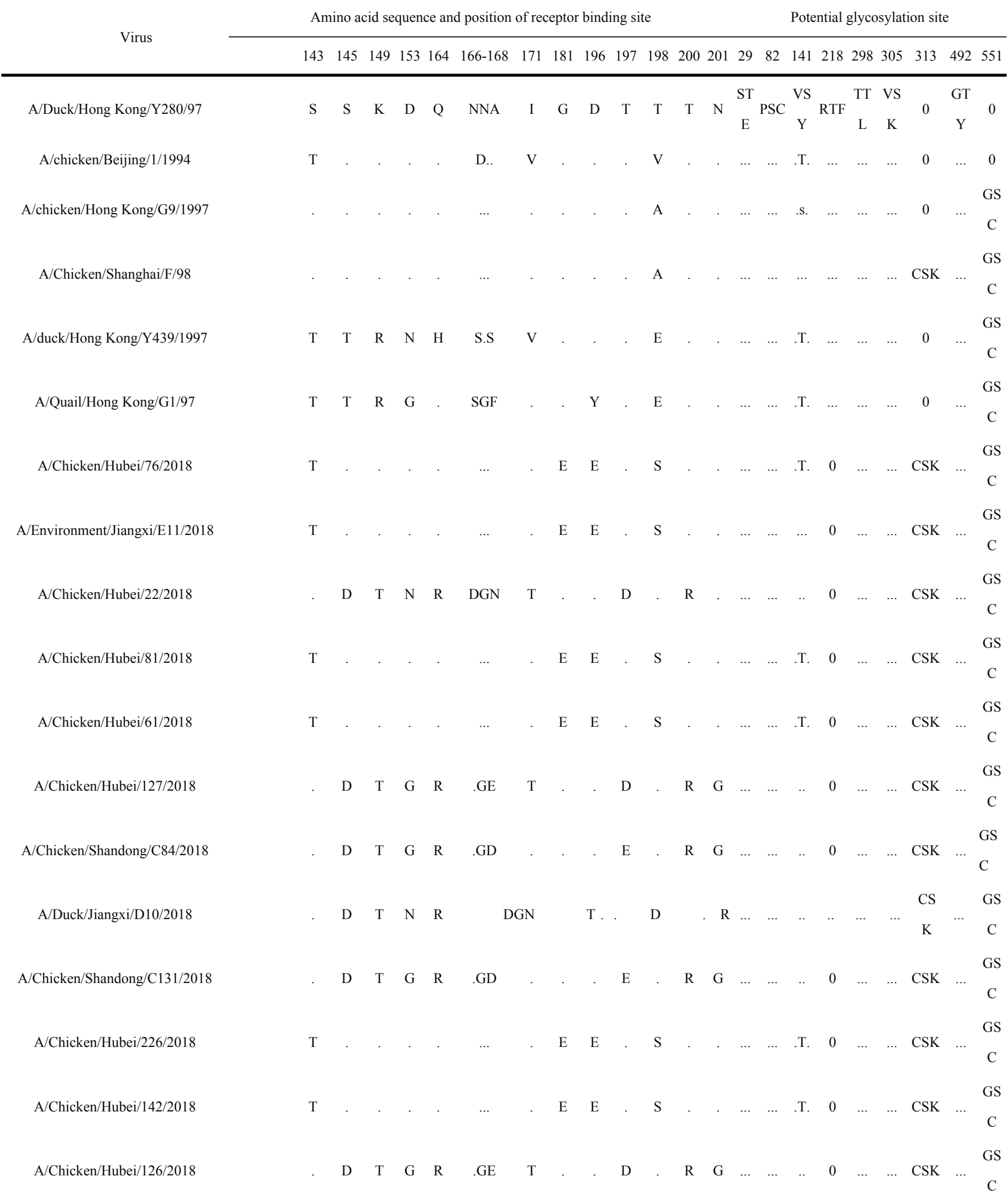


A/Chicken/Hubei/147/2018

A/Chicken/Hubei/149/2018

A/Chicken/Hubei/251/2018

A/Chicken/Shandong/C54/2018

A/Chicken/Hubei/95/2018

A/Chicken/Shandong/C82/2018

A/Chicken/Hubei/261/2018

A/Chicken/Hubei/80/2018

A/Chicken/Hubei/160/2018

A/Chicken/Shandong/C107/2018

A/Chicken/Shandong/C169/2018

A/Chicken/Jiangxi/C15/2018

A/Chicken/Shandong/C79/2018

A/Environment/Jiangxi/E15/2018

A/Chicken/Jiangxi/C19/2018

A/Chicken/Shandong/C80/2018

A/Chicken/Jiangxi/C16/2018

A/Chicken/Hubei/146/2018

A/Chicken/Hubei/78/2018
$\mathrm{T}$

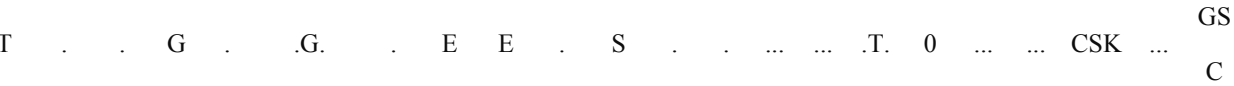

GS

$\begin{array}{lllllllllllllllllllllllllllllllll}\mathrm{D} & \mathrm{T} & \mathrm{G} & \mathrm{R} & \mathrm{GE} & \mathrm{T} & . & . & \mathrm{D} & . & \mathrm{R} & \mathrm{G} & \ldots & \ldots & . & 0 & \ldots & \ldots & \mathrm{CSK} & \ldots & & \end{array}$

$\begin{array}{lllll}D & \mathrm{~T} & \mathrm{G} & \mathrm{R} & \mathrm{GD}\end{array}$

E

R G $\quad \ldots \quad 0 \quad$ CSK $\quad \ldots \quad$ GS

D $\quad \mathrm{T} \quad \mathrm{G} \quad \mathrm{R} \quad$..D

E .

$\begin{array}{lllllllllll}\mathrm{R} & \mathrm{G} & \ldots & \ldots & \text {.T. } & 0 & \ldots & \ldots & \mathrm{CSK} & \ldots & \end{array}$

$\mathrm{T}$

$\begin{array}{lllllllllllllll}\mathrm{E} & \mathrm{E} & . & \mathrm{S} & \cdot & . & \ldots & \ldots & . . & 0 & \ldots & \ldots & \mathrm{CSK} & \ldots & \mathrm{GS} \\ & & & & & & & & & & & & \end{array}$

$\begin{array}{lllll}D & \mathrm{~T} & \mathrm{G} & \mathrm{R} & \mathrm{GD}\end{array}$

E .

R G .

.T. 0

CSK GS

$\begin{array}{lllll}D & \mathrm{~T} & \mathrm{G} & \mathrm{R} & \text { G. GD }\end{array}$

E

R G

$\mathrm{T}$ E E . S

T. $\quad 0 \quad \ldots \quad \ldots \quad$ CSK $\quad$ GS

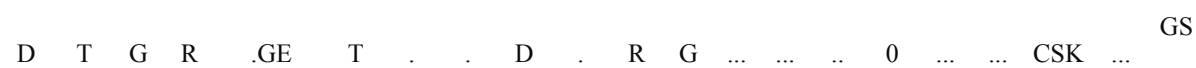

C

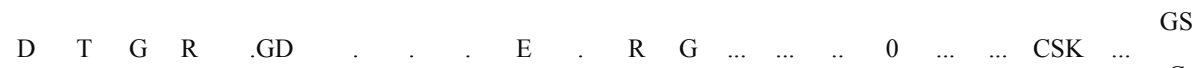

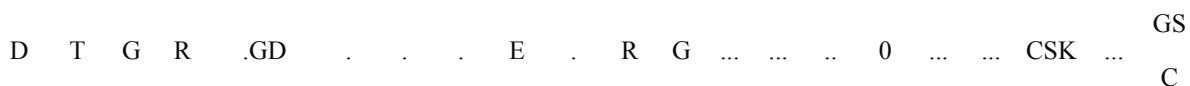

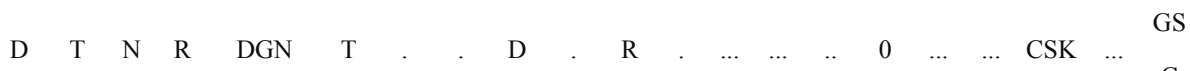

C

$\begin{array}{lllllllllllllllllllllllllll}\mathrm{D} & \mathrm{T} & \mathrm{G} & \mathrm{R} & \mathrm{GD} & . & & . & & & \mathrm{E} & . & \mathrm{R} & \mathrm{G} & \ldots & \ldots & \ldots & 0 & \ldots & \ldots & \mathrm{CSK} & \ldots & \mathrm{GS}\end{array}$

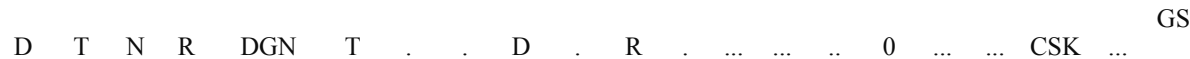

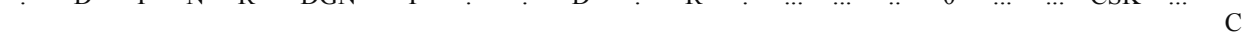

$\begin{array}{llllllllllllllllllllllllllllll}\mathrm{D} & \mathrm{T} & \mathrm{N} & \mathrm{R} & \mathrm{DGN} & \mathrm{T} & . & . & \mathrm{D} & . & \mathrm{R} & . & \ldots & \ldots & . & 0 & \ldots & \ldots & \mathrm{CSK} & \ldots & & \mathrm{GS}\end{array}$

(n)

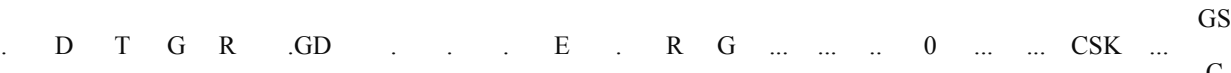

$\begin{array}{lllllllll} & & & & \\ \mathrm{D} & \mathrm{T} & \mathrm{N} & \mathrm{DGN} & \mathrm{T} & \mathrm{D} & \mathrm{R} & 0 & \mathrm{CSK}\end{array}$

$\begin{array}{llll} & \\ \mathrm{C} & \end{array}$

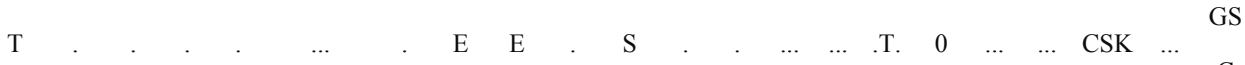

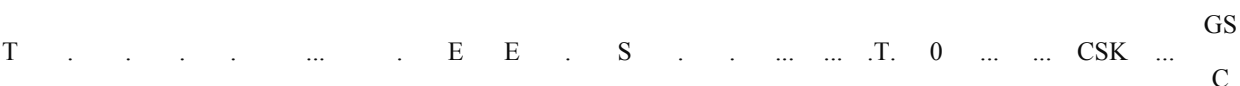


A/Chicken/Jiangxi/C11/2018

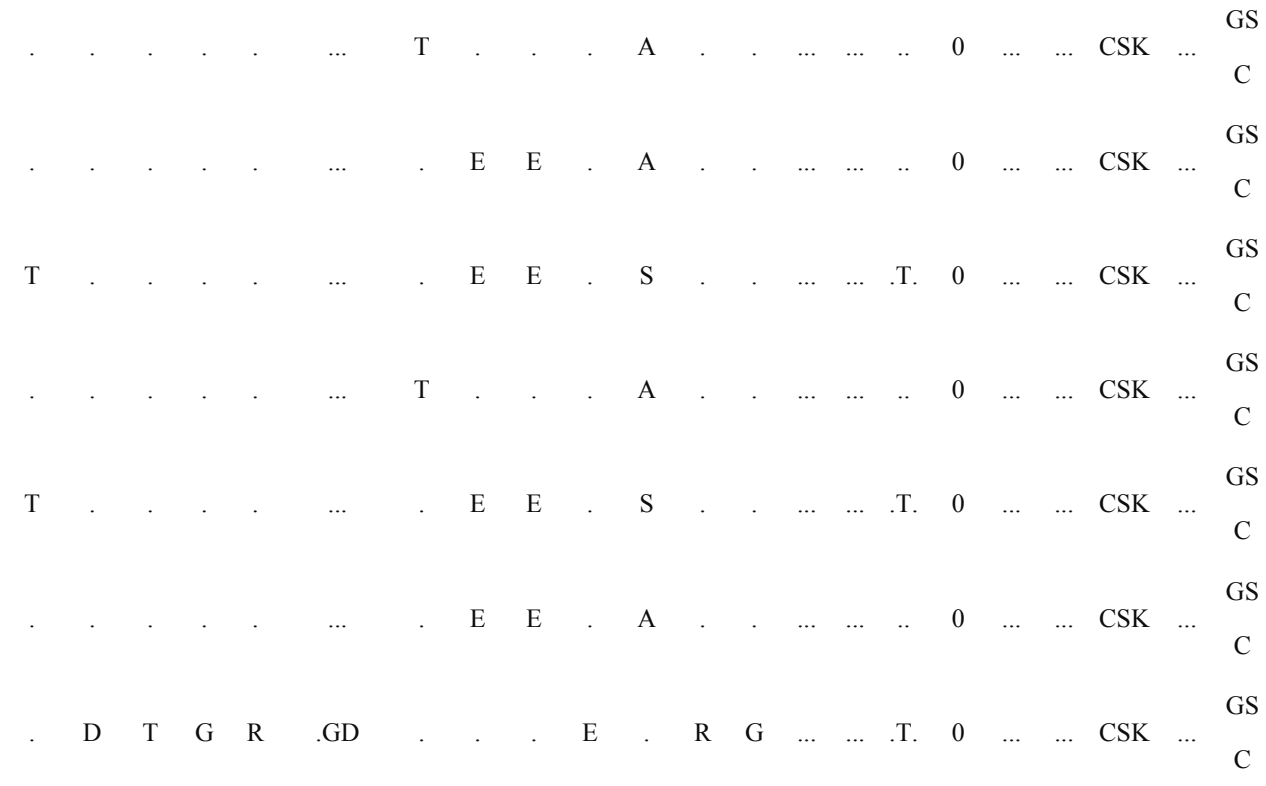

A/Chicken/Shandong/C126/2018

$\mathrm{T}$

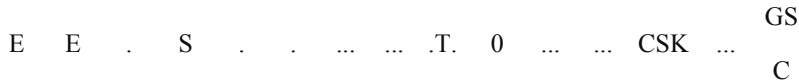

A/Chicken/Hubei/65/2018

$\mathrm{T}$

$\begin{array}{llllllllllllllll}\mathrm{E} & \mathrm{E} & \cdot & \mathrm{S} & \cdot & \ldots & \ldots & \ldots & . \mathrm{T} & 0 & \ldots & \ldots & \mathrm{CSK} & \ldots & \mathrm{GS} \\ \end{array}$

A/Duck/Jiangxi/D1/2018

$\mathrm{T}$

E E . S

GS

A/Chicken/Hubei/90/2018

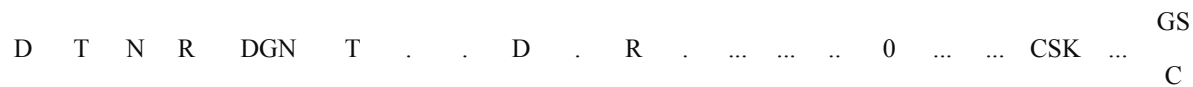

A/Chicken/Hubei/169/2018

$\begin{array}{lllll}D & \mathrm{~T} & \mathrm{G} & \mathrm{R} & \mathrm{GD}\end{array}$

$\begin{array}{llllllllllllll}\mathrm{E} & . & \mathrm{R} & \mathrm{G} & \ldots & \ldots & . . & 0 & \ldots & \ldots & \mathrm{CSK} & \ldots & \mathrm{GS} \\ & & & & & & & & & & & \mathrm{C}\end{array}$

A/Chicken/Hubei/77/2018

$\mathrm{T}$

$\begin{array}{llllllllllll}\mathrm{E} & \mathrm{E} & \mathrm{S} & \ldots & \ldots & . \mathrm{T} & 0 & \ldots & \ldots & \mathrm{CSK} & & \text { GS }\end{array}$

A/Chicken/Jiangxi/C42/2018

D $\quad \mathrm{T} \quad \mathrm{G} \quad \mathrm{R} \quad$ GD

$\begin{array}{llllllllllllll}\mathrm{E} & . & \mathrm{R} & \mathrm{G} & \ldots & \ldots & . . & 0 & \ldots & \ldots & \mathrm{CSK} & \ldots & \mathrm{GS} \\ & & & & & & & & & & & \mathrm{C}\end{array}$

A/Goose/Jiangxi/G1/2018

$\mathrm{T}$ $\begin{array}{llllllllllllllllll}\mathrm{E} & \mathrm{E} & . & \mathrm{S} & . & . & \ldots & \ldots & . \mathrm{T} & 0 & \ldots & \ldots & \mathrm{CSK} & \ldots & & \end{array}$

A/Chicken/Hubei/152/2018

$\begin{array}{llllllllllllllllllllllllllll}\mathrm{D} & \mathrm{T} & \mathrm{N} & \mathrm{R} & \mathrm{DGN} & \mathrm{T} & . & . & \mathrm{D} & . & \mathrm{R} & & \ldots & \ldots & \ldots & \ldots & 0 & \ldots & \ldots & \mathrm{CSK} & \ldots & \mathrm{GS}\end{array}$

A/Chicken/Hubei/262/2018

$\mathrm{T}$

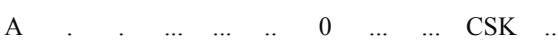

550 “.” represents that the site at which the amino acid is identical to A/Duck/Hong Kong/Y280/97 (H9N2) virus; "0" indicates a site

551 at which the potential glycosylation site was absent. 
553

554

555

556

557

558

559

560

561

562

563

564

565

566

567

568

\section{Figure Legends}

Figure 1. Phylogenetic relationship between the HA (A) and NA (B) genes of H9N2 AIVs

detected in this study and reference strains. The tree was constructed using a neighbor-joining method in MEGA package (version 7.0). Note: A) The HA sequences of prevalent H9N2 isolates are indicated with a solid black triangle, and the HA sequences of H9N2 vaccines are

labeled with a red triangle. B) The NA sequences of prevalent H9N2 isolates are marked with solid black triangles, and the NA sequences of prevalent H9N2 vaccines are marked with red triangles.

Figure 2. HI test results. Fifty-five H9N2 AIV isolates were used as antigens for the HI test using a standard antiserum against $\mathrm{H} 5, \mathrm{H} 7$, and $\mathrm{H} 9$ subtype AIVs. The number of samples in which the virus reacted with the $\mathrm{H} 5, \mathrm{H} 7$, and $\mathrm{H} 9$ subtype antiserum is shown.

Figure S1. Sequences' homology rates between the field viruses and vaccine strains. The sequence homology was analyzed using DNASTAR Lasergene71 Megalign software. (A) Homology rates in HA sequences between field isolates and reference strain; (B) homology rates 
569 in HA sequences between vaccine strains and field isolates; (C) homology rates in NA sequences

570 between field isolates and reference strains; (D) homology rates in the NA sequence between

571 vaccine strains and field isolates. 


\section{Figure 1}

Phylogenetic relationship of the HA (A) and NA (B) genes of H9N2 AIVs detect in this study and reference strains.

The tree was constructed by neighbor-joining method using MEGA package version 7.0.

Note: A) the HA sequences of prevalent H9N2 isolates were marked with filled black triangle, and the HA sequences of H9N2 vaccines were labelled with red triangle. B) The NA sequences of prevalent H9N2 isolates were marked with filled black triangles, and the NA sequences of prevalent H9N2 vaccines were labelled with red triangle. 
A

- A/chicken/Suqian/SQ1602/2016

$55{ }_{67} \mathrm{~L}$ A/chicken/Jingmen/JM0305/2017 - A/chicken/Ganzhow/GZ86/2016

35 _ Achicken/Fujian/S1XA35/2017

Isoletes from Jiangxi

A/chicken/Xiamen/09/2015

A/chicken/Sichuan/LMC/2016

s. A/chicken/Guizhou/QZ/2015

80 Achicken/Yuhuan $/$ H $15 / 2016$

59 19

L A A/chicken/Jiangsu/WJ57/2012

A/chicken/Hubei/ZYSJF15/2016

74 - A/chicken/Guangdong/ZW/2012

97 2 A/chicken/Shandong/P6/2012

$99-\Delta$ Achicken/Guangdong/ $4 / 2009$

๓L A Achicken/Shandong/HU/2010

93 Achicken/Hubei/TS1/2011

62 A 1 A/chicken/Jilin/BHJ/2010

A/chicken/HongKong/TP38/03
A/chicken/Shandong/YB06/2006
A/chicken/Shandong/x327/2007
A/chicken/Shenyang/W2/2011

A/chicken/HongKong/TP38/03
A/chicken/Shandong/YB06/2006
A/chicken/Shandong/x327/2007
A/chicken/Shenyang/W2/2011

4.2 .6

_ ADuck/Hong Kong/ Y280/97

23 - Alchicken/Hebeil 1/2006

99 A/chicken/Yangzhou/YZ/2000

76 - A AChicken/Guangdong/SS/94

69 _ A/Chicken/ShanghailF/98

icken/Beijing/1/1994

Auail/Hong Kong/G1/97

Aturkey/Wisconsin/1/1966

Adduck/HK/784/1979

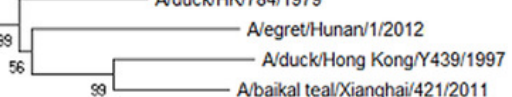

B Isolates from 201

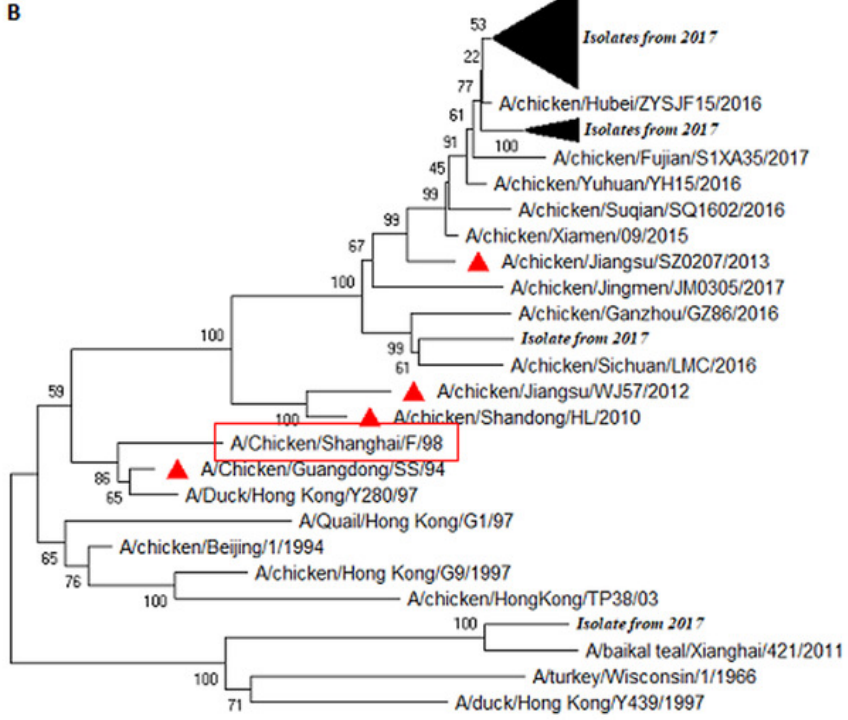


Figure 2

Result of $\mathrm{HI}$ test.

Fifty five H9N2 AIV isolates were used as antigen for the HI test using standard antiserum against $\mathrm{H} 5, \mathrm{H} 7$ and $\mathrm{H} 9$ subtype AIV, respectively. The number of samples in which the virus reacted with $\mathrm{H} 5, \mathrm{H} 7$ and $\mathrm{H} 9$ subtype antiserum was shown.

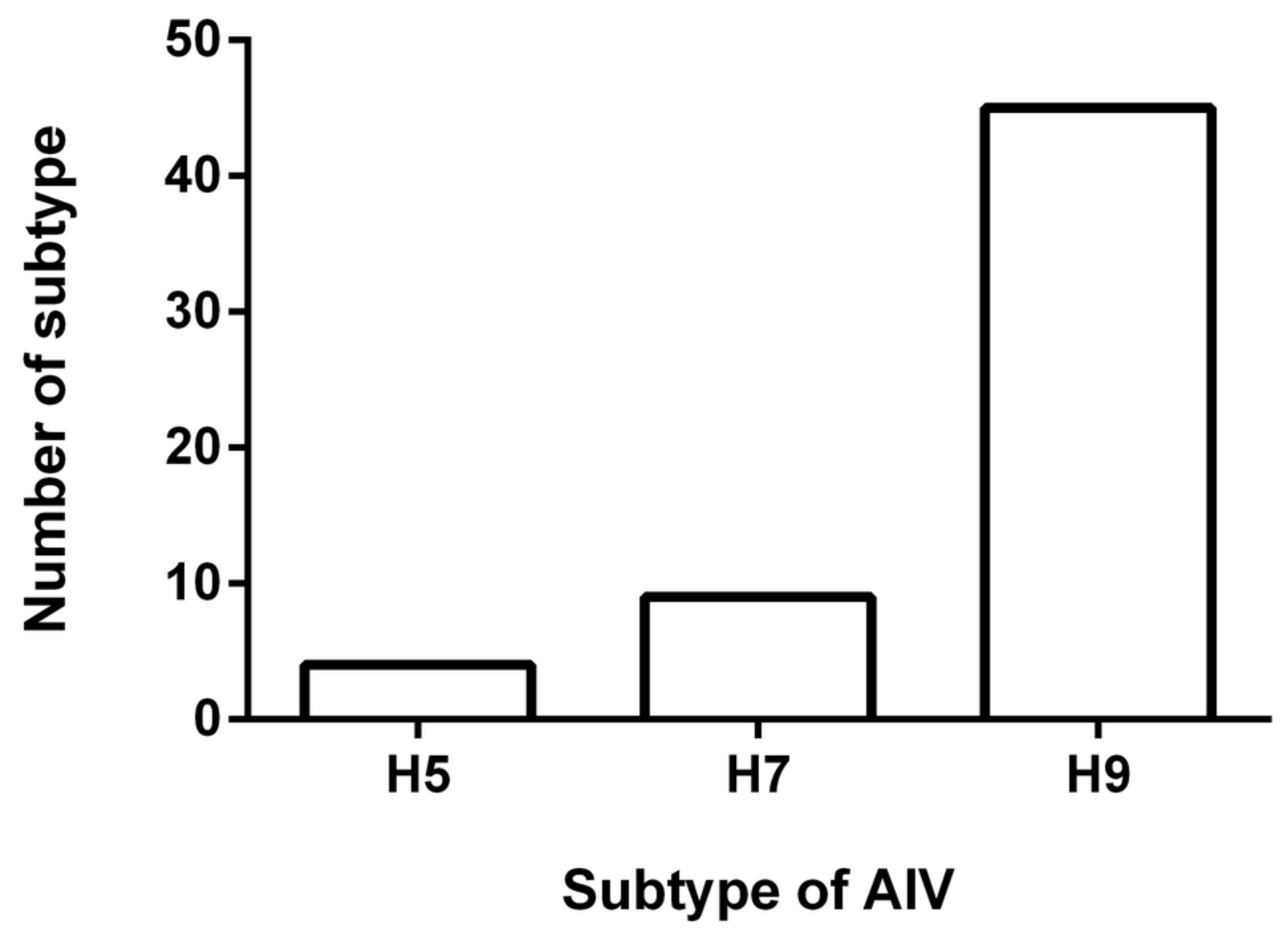

